Article

\title{
Multi-Stage Transmission Network Planning Considering Transmission Congestion in the Power Market
}

\author{
Yixin Huang ${ }^{1}$, Xinyi Liu ${ }^{1}$, Zhi Zhang ${ }^{1}{ }^{\oplus}$, Li Yang ${ }^{1, *}$, Zhenzhi Lin ${ }^{1,2}$, Yangqing Dan ${ }^{3}$, Ke Sun ${ }^{3}$, \\ Zhou Lan ${ }^{3}$ and Keping Zhu ${ }^{3}$ \\ 1 School of Electrical Engineering, Zhejiang University, Hangzhou 310027, China; ee_hyx@zju.edu.cn (Y.H.); \\ ee_lxy@126.com (X.L.); zhangzhi_EE@zju.edu.cn (Z.Z.); linzhenzhi@zju.edu.cn (Z.L.) \\ 2 School of Electrical Engineering, Shandong University, Jinan 250002, China \\ 3 State Grid Zhejiang Economic Research Institute, Hangzhou 310016, China; danyangqing@aliyun.com (Y.D.); \\ sunke_huayun@126.com (K.S.); lanzhou_zjjyy@163.com (Z.L.); zhukeping@163.com (K.Z.) \\ * Correspondence: eeyangli@zju.edu.cn; Tel.: +86-137-7786-4769
}

Received: 2 August 2020; Accepted: 14 September 2020; Published: 18 September 2020

\begin{abstract}
The uncertainty of generation and load increases in the transmission network in the power market. Considering the transmission congestion risk caused by various uncertainties of the transmission network, the optimal operation strategies of the transmission network under various operational scenarios are decided, aiming for the maximum of social benefit for the evaluation of the degree of scenario congestion. Then, a screening method for major congestion scenario is proposed based on the shadow price theory. With the goal of maximizing the difference between the social benefits and the investment and maintenance costs of transmission lines under major congestion scenarios, a multi-stage transmission network planning model based on major congestion scenarios is proposed to determine the configuration of transmission lines in each planning stage. In this paper, the multi-stage transmission network planning is a mixed integer linear programming problem. The DC power flow model and the commercial optimization software CPLEX are applied to solve the problem to obtain the planning scheme. The improved six-node Garver power system and the simplified 25-node power system of Zhejiang Province, China are used to verify the effectiveness of the proposed multi-stage planning model.
\end{abstract}

Keywords: multi-stage transmission network planning; power market; transmission congestion; scenario screening

\section{Introduction}

Nowadays, China's power market system is in the accelerating progress of changing from monopoly and regulation to competition [1,2]. The processes of generation, transmission, distribution, and sales in the power market are separated, and the behaviors of multiple participants are becoming more independent and complex [3-5]. At the same time, with the energy structure transition and the development of a smart grid in China [6,7], the uncertainty of a transmission network further increases, which generates many new operational scenarios [8-10]. When the transmission capacity of the network is insufficient, the power flow through the transmission line is limited due to the physical constraints of a secure and stable operation, and the transmission congestion then takes place [11,12]. Users in transmission congestion areas have to buy more expensive electricity, which makes the locational marginal price (LMP) higher than the system marginal generation cost and increases the operation cost of transmission network. The transmission congestion limits the role of transmission network in optimizing the allocation of network resources and improving the energy efficiency in the 
power market [13]. It is necessary to study the transmission network planning problem considering transmission congestion in the power market.

In recent years, research work has been carried out on transmission network planning of the power market. In the power market, the power price is quoted by generators and users according to their generation costs and consumption benefits, which forms correct price signals and guides the optimal allocation of network resources $[14,15]$. Based on the game theory $[16,17]$, the transmission network planning method considering the behavior of generators and the planning decision of the transmission network is studied. In [18,19], a transmission network expansion planning model and a coordinated generation and transmission planning model are established, considering the maximum of social welfare and generators' benefit. In [20], considering the influence of short-term bidding strategies and long-term network expansion planning of generators, a four-level planning model of generation bidding, market settlement, generation planning, and network planning of the power market is proposed. The transmission network planning method based on game theory reflects the behavior strategy of generators in the power market and balances the interests of the multiple market participants [21]. However, the research work above does not consider the impact of generators' market power on the transmission network. When the transmission capacity of transmission network is limited, generators can artificially create transmission congestion to increase revenue, which leads to the rise of electricity price and the failure of electricity effective distribution [22]. In the power market, the LMP is used to measure the value of electric energy at different positions in the power system under various operation scenarios and reflect the severity of transmission congestion [23-25]. In [26], a novel evaluation method for operation efficiency of the transmission network is proposed based on LMP. A security-constrained unit commitment model considering the impact of mobility of battery-based energy storage transportation system is proposed in [27] to reduce the overall cost of power delivery by transporting the electricity from low LMP areas to high LMP areas. A two-stage algorithm is proposed in [28] to analyze the effect of carbon emission quota allocation on the LMP of day-ahead electricity markets. In [29], a novel electricity market-clearing mechanism based on locational marginal prices is proposed considering the uncertainties of generation and load. The above studies indicate the guiding role of LMP in congestion management from the perspective of network operation and power market. However, the role of LMP in guiding transmission network planning and evaluating the corresponding benefit in alleviating transmission congestion under various operation scenarios is not exerted fully and needs further research.

In the power market, the transmission congestion risks should be mitigated through transmission network planning [30,31]. In [32], the transmission cost allocation is considered for the proposed tri-level transmission network planning model, which effectively defers the expansion planning and reduces the investment cost. In [33], the transmission network is co-optimized with the merchant electrochemical storage in the market environment, which helps to present the interaction between the transmission network expansion planning and the storage configuration. In [34], a multi-objective transmission network planning model is established with minimum investment, congestion, and risk costs. The transmission network planning based on probabilistic analysis should be studied considering the uncertainties of natural environment, generators, loads, and policies on power generation, transmission, and demand side. In [35], the point estimation method and the Monte Carlo method are jointly applied to describe the uncertainty of intermittent energy and load of the transmission network with high proportion of wind power. Then, a multi-objective transmission network expansion planning model considering the investment cost, risk cost, and congestion cost of the transmission network is established. In [36,37], the stochastic programming theory and scenario analysis method are used to describe the uncertainty of power generation, investment, and load demand of the transmission network on a long-time scale, as well as the uncertainty of distributed generation and load on a short-time scale. Then, the joint planning models of transmission network and energy storage are established. However, the transmission network planning method based on uncertainty theory is time consuming in computation. Only a few types of uncertain risk sources 
are taken into consideration and their correlations are not involved. The transmission network model based on scenario analysis describes the uncertainties as multiple individual probabilistic scenarios, which reduces the difficulty of solving while considering the coupling of uncertain risks [38]. The uncertainties of renewable generation and load demand are represented by a set of scenarios through rough fuzzy clustering in the flexible transmission network expansion planning of [39]. In [40], the scenario identification index is defined to determine the important scenarios for solving the stochastic transmission expansion planning problem with $\mathrm{N}-1$ contingency analysis. In [41], the concept of an extreme scenario of wind power is proposed and a two-stage transmission network planning model based on Benders decomposition is then established. In [42], a scenario-based transmission expansion planning model is established considering the massive scenarios based on the proposed cost-oriented dynamic scenario clustering method. However, the current researches do not consider the transmission congestion scenarios caused by multiple uncertainties from power market. Thus, it is necessary to carry out the network planning considering transmission congestion scenarios to improve the economy of the transmission network planning scheme in the power market.

Aiming at the above problems, a multi-stage transmission network planning method considering transmission congestion in the power market is presented in this paper. With the goal of maximizing social benefit, the optimal dispatch problem under each operation scenario is simulated and solved. Based on the shadow price theory, a novel screening method for major congestion scenarios is proposed to provide planning scenarios for the transmission network planning. A multi-stage planning model for a transmission network considering transmission congestion is established, with the maximum difference between the social benefits and the investment and maintenance costs of transmission line under severe congestion scenarios. The proposed model based on DC power flow is a mixed integer linear programming problem, which is solved by the commercial optimization software CPLEX. The validity of the proposed model is verified through the case study based on the improved six-node Garver power system and simplified 25-node power system of Zhejiang Province, China.

\section{Transmission Congestion Scenario Screening Based on Shadow Price Theory}

The location and severity of transmission congestion are related to the operational scenarios in the transmission network. It is necessary to focus on the operational problems under transmission congestion scenarios in the planning decision-making process to improve the efficiency and economic benefit of planning. With the development of the power market, the operational scenarios of the power system tend to be diversified and complicated, which brings great challenges to the search for major congestion scenarios with planning value. In this section, the optimal operation of transmission network in the power market is discussed with the goal of the maximization of social benefit. In transmission network operation and planning, the DC power flow model is used to obtain the LMP within the acceptable range, assuming that the voltage variance and line losses are neglected [22,43]. Considering the node power balance constraint, power flow constraint, line capacity constraint, generator output constraint, and power loss constraint, the active power of generators and users' load under various transmission network scenarios are decided to decompose the LMP. Based on the shadow price theory, the index for transmission congestion degree evaluation and the screening method of major congestion scenario are proposed.

\subsection{Economic Dispatching Model of Transmission Network in the Power Market}

To realize the economic allocation of electricity energy considering the interests of generators and users in the power market, the economic dispatching model of the transmission network aims at maximizing the social benefit $C^{s b}$. The objective function includes the generation cost of generator and users' benefit, which is expressed as:

$$
\max C^{s b}=\sum_{i \in \Omega_{\text {node }}} P_{i}^{\text {load }} c_{i}^{\text {load }}-\sum_{i \in \Omega_{\text {node }}} \sum_{g \in \Omega_{i}^{\text {gen }}} P_{i, g}^{\text {gen }} c_{i, g}^{\text {gen }} .
$$


The constraints of the transmission network economic dispatching model are presented as follows:

1. Node power balance constraint

$$
\sum_{g \in \Omega_{i}^{g e n}} P_{i, g}^{g e n}+\sum_{i j \in \Omega_{i}^{\text {line }}} P_{i j}^{\text {line }}=P_{i}^{d}
$$

2. Power flow constraint

$$
P_{i j}^{l i n e}=\sum_{k \in L_{i j}} P_{i j, k}^{l i n e}=\sum_{k \in L_{i j}} n_{i j, k} B_{i j, k}\left(\theta_{i}-\theta_{j}\right)
$$

3. Line capacity constraint

$$
-n_{i j, k} S_{i j, k}^{\max } \leq P_{i j, k}^{l i n e} \leq n_{i j, k} S_{i j, k}^{\max }
$$

4. Generator power constraint

$$
P_{i, g}^{g e n, \min } \leq P_{i, g}^{g e n} \leq P_{i, g}^{g e n, \max }
$$

5. Phase angle constraint of equilibrium node

$$
\theta_{\text {ref }}=0
$$

6. Power losses constraint

$$
\left(1-\varepsilon_{i}^{E N S}\right) P_{i}^{d} \leq P_{i}^{\text {load }} \leq P_{i}^{d}
$$

\subsection{LMP Decomposition Based on Shadow Price Theory}

The LMP in the transmission network is defined as the marginal cost or revenue when the unit load demand of the node changes [44]. In the power market, LMP can provide price signals for market participants, realize fair trade, help transmission companies to solve transmission congestion problems, and guide transmission network planning [45]. When solving the optimal power flow economic dispatching problem of the transmission network, the extended Lagrangian function is constructed to calculate the Lagrangian multiplier of each constraint, which represents the shadow price of the network resources (i.e., lines and generators) associated with the constraint $[46,47]$. The expression of the extended Lagrangian function is expressed as follows:

$$
\begin{aligned}
& L=\sum_{i \in \Omega_{\text {node }}} P_{i}^{\text {load }} c_{\text {load }}\left(P_{i}^{\text {load }}\right)-\sum_{i \in \Omega_{\text {node }}} \sum_{g \in \Omega_{i}^{\text {gen }}} P_{i, g}^{\text {gen }} c_{\text {gen }}\left(P_{i, g}^{\text {gen }}\right)+\sum_{i \in \Omega_{\text {node }}} \lambda_{i}\left(\sum_{g \in \Omega_{\text {gen, }}} P_{i, g}^{\text {gen }}-P_{i}^{d}\right) \\
& +\sum_{i \in \Omega_{\text {node }}} \sum_{k \in L_{i j}} \mu_{i j}\left(P_{i j}^{\text {line }}-\sum_{k \in L_{i j}} n_{i j, k} B_{i j, k}\left(\theta_{i}-\theta_{j}\right)\right) \\
& +\sum_{i \in \Omega_{\text {node }}} \sum_{k \in L_{i j}} \overline{v_{i j, k}}\left(P_{i j, k}^{\text {line }}-n_{i j, k} S_{i j, k}^{\max }\right)+\sum_{i \in \Omega_{\text {node }}} \sum_{k \in L_{i j}} v_{i j, k}\left(-n_{i j, k} S_{i j, k}^{\max }-P_{i j, k}^{\text {line }}\right) \\
& +\sum_{i \in \Omega_{\text {node }}} \sum_{g \in \Omega_{\text {gen }, i}} \overline{\tau_{i, g}}\left(P_{i, g}^{g e n}-P_{i, g}^{g e n, \max }\right)+\sum_{i \in \Omega_{\text {node }}} \sum_{g \in \Omega_{\text {gen }, i}} \tau_{i, g}\left(P_{i, g}^{g e n, \text { min }}-P_{i, g}^{g e n}\right) \\
& +\pi \theta_{\text {ref }}+\sum_{i \in \Omega_{\text {node }}} \overline{\omega_{i}}\left(P_{i}^{\text {load }}-P_{i}^{d}\right)+\sum_{i \in \Omega_{\text {node }}} \omega_{i}\left[\left(1-\varepsilon_{i}^{E N S}\right) P_{i}^{d}-P_{i}^{\text {load }}\right]
\end{aligned}
$$

The partial derivatives of the extended Lagrange function for each node is expressed as follows:

$$
\frac{\partial L}{\partial P_{i}^{\text {load }}}=c_{\text {load }}\left(P_{i}^{\text {load }}\right)+P_{i}^{\text {load }} \frac{\partial c_{\text {load }}\left(P_{i}^{\text {load }}\right)}{\partial P_{i}^{\text {load }}}-\lambda_{i}+\sum_{k \in L_{i j}} \mu_{i j} \frac{\partial P_{i j}^{\text {line }}}{\partial P_{i}^{\text {load }}}+\sum_{k \in L_{i j}}\left(\overline{v_{i j, k}}-\underline{v_{i j, k}}\right) \frac{\partial P_{i j, k}^{\text {line }}}{\partial P_{i}^{\text {load }}}+\overline{\omega_{i}}-\underline{\omega_{i}}
$$


Based on the Karush-Kuhn-Tucker (KKT) optimality condition $[48,49]$, the LMP of node $i$ is expressed as:

$$
\begin{aligned}
L M P_{i}^{\text {load }} & =c_{\text {load }}\left(P_{i}^{\text {looad }}\right)+P_{i}^{\text {lood }} \frac{\partial c_{\text {load }}\left(P_{i}^{\text {load }}\right)}{\partial P_{i}^{\text {load }}} \\
& =\lambda_{i}-\sum_{k \in L_{i j}} \mu_{i j} \frac{\partial P_{i j}^{\text {line }}}{\partial P_{i}^{\text {load }}}-\sum_{k \in L_{i j}}\left(\overline{v_{i j, k}}-\underline{v_{i j, k}}\right) \frac{\partial P_{i j, k}^{\text {line }}}{\partial P_{i}^{\text {load }}}-\overline{\omega_{i}}+\underline{\omega_{i}}
\end{aligned}
$$

It can be seen that the LMP at load node includes the electric price at the reference node, Lagrange multipliers of the line congestion constraint, and the power losses constraint. The Lagrange multiplier represents the increment of the objective function $C^{\mathrm{sb}}$ when the $k$ th circuit of transmission corridor ij expands unit capacity. When the capacity of transmission lines is insufficient and the power flow exceeds the maximum limit, the Lagrange multipliers $\overline{v_{i j, k}}$ and $v_{i j, k}$ are not all zero. The larger $\overline{v_{i j, k}}$ or $v_{i j, k}$ is, the more serious the transmission congestion problem is, and the better the effect of line expansion is on alleviating transmission congestion.

The partial derivatives of the extended Lagrange function for each generator is expressed as follows:

$$
\frac{\partial L}{\partial P_{i, g}^{g e n}}=-c_{g e n}\left(P_{i, g}^{g e n}\right)-P_{i, g}^{g e n} \frac{\partial c_{g e n}\left(P_{i, g}^{g e n}\right)}{\partial P_{i, g}^{g e n}}+\lambda_{i}+\sum_{k \in L_{i j}} \mu_{i j} \frac{\partial P_{i j}^{\text {line }}}{\partial P_{i, g}^{g e n}}+\sum_{k \in L_{i j}}\left(\overline{v_{i j, k}}-\underline{v_{i j, k}}\right) \frac{\partial P_{i j, k}^{l i n e}}{\partial P_{i, g}^{g e n}}+\sum_{g \in \Omega_{g e n, i}}\left(\overline{\tau_{i, g}}-\underline{\tau_{i, g}}\right) .
$$

Therefore, the LMP of generator $g$ connected with node $i$, including the reference node price, the line congestion constraint shadow price and the generator output constraint shadow price, is expressed as:

$$
\begin{aligned}
L M P_{i, g}^{g e n} & =c_{g e n}\left(P_{i, g}^{g e n}\right)+P_{i, g}^{g e n} \frac{\partial c_{g e n}\left(P_{i, g}^{g e n}\right)}{\partial P_{i, g}^{g e n}} \\
& =\lambda_{i}+\sum_{k \in L_{i j}} \mu_{i j} \frac{\partial P_{i j}^{\text {gine }}}{\partial P_{i, g}^{g e n}}+\sum_{k \in L_{i j}}\left(\overline{v_{i j, k}}-\underline{v_{i j, k}}\right) \frac{\partial P_{i j, k}^{\text {line }}}{\partial P_{i, g}^{\text {gen }}}+\sum_{g \in \Omega_{g e n, i}}\left(\overline{\tau_{i, g}}-\underline{\tau_{i, g}}\right)
\end{aligned}
$$

The shadow prices of network resources in the economic dispatch problem of the transmission network are related to the Lagrange multipliers of constraints in the optimal power flow model, the marginal cost of generation, the marginal benefit of electricity consumption, and the flow transferring relativity factor. By decomposing the LMP at each node, the value of network resources is effectively evaluated to guide the planning and use of power network resources in the power market.

\subsection{Screening of Transmission Network Congestion Scenarios}

Since the new electric power restructuring, the trading volume of electricity within and across provinces in China continues to increase. The influence of the power market on the planning and operation of transmission network is expanding day by day. In addition to the traditional risk sources in the transmission network such as the integration of renewable energy, load fluctuation, and equipment failure [50], new risk sources from the power market such as plant-grid separation, electricity price fluctuation, and direct transaction between generators and users increase the risk degree of the transmission network congestion and the difficulty for transmission companies to coordinate generation and network resources. Generating as many transmission network operation scenarios as possible based on scenario analysis methods and taking them into consideration in planning decision help to fully simulate various potential congestion risks of transmission network, which ensures the economy of the planning scheme. However, the more scenarios there are, the more variables and constraints will be in the planning model, which most likely leads to the dimension disaster and reduces the solving efficiency. Scenarios such as the maximum load, high probability, and failure scenarios are set artificially in the existing transmission network planning method, which cannot objectively evaluate the severity of the congestion problem under various operation scenarios, leading to the neglect of potential congestion scenarios. 
Under the transmission congestion scenario, there is a price difference between the two ends of the transmission line, which results in transmission congestion surplus. The transmission congestion surplus is related to the shadow prices (i.e., Lagrange multipliers) $\mu_{i}, \overline{v_{i j, k}}$ and $v_{i j, k}$ in the optimal power flow model, and the flow transferring relativity factor $H_{i j}=\frac{\partial P_{i j}^{\text {line }}}{\partial P_{i}^{\text {gen }}}=\frac{\partial P_{i j}^{\text {line }}}{\partial P_{i}^{\text {load }}}$. Assuming that the network frame is determined, the $\mu_{i}, \overline{v_{i j, k}}$ and $v_{i j, k}$ can be used to reflect the severity of the transmission congestion. Therefore, an evaluation index for transmission congestion degree is proposed based on the shadow price. Further, a novel screening method for major congestion scenario is proposed to guide transmission network planning considering transmission congestion.

$$
\begin{aligned}
\eta_{s} & =p_{s} \varphi_{s} \\
& =p_{s} \sum_{i \in \Omega_{\text {node }}} \sum_{i j \in \Omega_{\text {line }}, i} \sum_{k \in L_{i j}}\left(\mu_{s, i j}+\overline{v_{s, i j, k}}+\underline{v_{s, i j j, k}}\right)
\end{aligned}
$$

The proposed transmission congestion degree of scenario comprehensively considers the two dimensions (i.e., probability and impact) of the risk. It objectively describes the transmission congestion risk of the scenario and reflects the influence of the operation scenario on the network planning. The scenario with sufficient planning value should be added into the planning scenario set $\Omega_{\text {plan }}$ which is expressed as:

$$
\Omega_{\text {plan }}=\left\{s * \mid \eta_{s^{*}} \geq \eta_{0}\right\} .
$$

According to (14), the scenario with a transmission congestion degree greater than the transmission congestion threshold $\eta_{0}$ is the major congestion scenario and is included into the planning scenario set; otherwise the scenario is the minor congestion scenario and does not need to be considered in the planning problem. The transmission congestion scenario screening provides actual transmission congestion information for the transmission network planning based on the simulation results of transmission network operation, which helps to achieve better planning results.

\section{The Network Planning Model Considering Transmission Congestion}

In order to improve the ability of transmission network planning model to mitigate the risk of transmission congestion, transmission network planning considering major congestion scenarios is carried out according to the optimized dispatching results of operation scenarios and the screening results of congestion scenarios based on the economic dispatching model. Then, the major congestion scenario is evaluated and screened again based on the current planning scheme. After iterative optimization planning, the optimal multi-stage network frame planning scheme is obtained.

\subsection{Multi-stage Planning Model of Transmission Network Considering Major Congestion Scenarios}

The transmission network planning model proposed in this paper starts from the point of view of the transmission company, which undertakes social responsibility while deciding the time and circuit number of transmission corridors to be built in the transmission network planning. For multi-stage transmission network planning, the net present value of the total cost in the planning period considers the time benefit, assuming that all cost components occur at the end of each planning stage. The objective function of the planning model includes transmission line investment cost, transmission line maintenance cost and social benefits of the transmission network under major congestion scenario, which is expressed as follows: 


$$
\begin{aligned}
& \underset{\Omega_{\text {dec }}}{\max C_{\text {total }}}=\sum_{t=1}^{N_{\text {plan }}}\left[\zeta_{t}\left(T_{h r} \sum_{s \in \Omega_{\text {plan }, t}} p_{s} C_{s}^{s b}-C_{t}^{o m}\right)-\sigma C_{t}^{\text {inv }}\right] \\
& =\sum_{t=1}^{N_{\text {plan }}} \mid \zeta_{t}\left(T_{h r} \sum_{s \in \Omega_{\text {plan }, t}} p_{s}\left(\sum_{i \in \Omega_{\text {node }}} P_{s, i}^{\text {load }} c_{s, i}^{\text {load }}-\sum_{i \in \Omega_{\text {node }}} \sum_{g \in \Omega_{i}^{\text {gen }}} P_{s, i, g}^{\text {gen }} c_{s, i, g}^{\text {gen }}\right)-\sum_{i \in \Omega_{\text {node }}} \sum_{i \in \Omega_{\text {line, }}} \sum_{k \in L_{i j}} c_{i j, k}^{o m} n_{t, i j, k}\right) \text {, } \\
& \left.-\sigma \sum_{i \in \Omega_{\text {node }}} \sum_{i j \in \Omega_{\text {line, }}} \sum_{k \in L_{i j}} c_{i j, k}^{i n v} x_{t, i j, k}\right] ; \quad \Omega_{\text {dec }}=\left\{P_{s, i}^{\text {load }}, P_{s, i, g}^{g e n}, n_{t, i j, k}, x_{t, i j, k}\right\} \\
& \zeta_{t}=(1+r)^{-t \times \frac{T_{\text {plan }}}{N_{\text {plan }}},} \\
& \sigma=\frac{r(1+r)^{T_{\text {line }}}}{(1+r)^{T_{\text {line }}}-1} .
\end{aligned}
$$

Constraints of the transmission network planning model are presented as follows:

1. Constraints on the number of new lines

Each transmission corridor allows the construction of a limited number of transmission lines, i.e.,

$$
0 \leq \sum_{t=1}^{N_{\text {plan }}} \sum_{k \in L_{i j}} x_{t, i j, k} \leq \overline{x_{i j}} .
$$

2. Timing constraints of transmission line construction

For the $k$ th candidate circuit of transmission corridor $i j$, once the construction is selected, it cannot be dismantled, i.e.,

$$
n_{t-1, i j, k} \leq n_{t, i j, k} .
$$

3. Constraints on the annual cost of transmission network investment

There are budgetary constraints on the investment costs of transmission lines at each planning stage, i.e.,

$$
C_{t}^{i n v} \leq C_{t}^{\text {bud }} .
$$

4. Constraints on the security operation of transmission network

The transmission network planning scheme should satisfy the security operation constraints (2)-(7).

\subsection{Iterative Solution Process of Transmission Network Optimization Planning}

The iterative solution process of the transmission network planning method proposed in this paper is shown in Figure 1. The initial transmission network and investment parameters and the power market bidding parameters are input into the bi-level collaborative planning as basic data. Before each iteration of transmission network planning, it is necessary to solve the economic dispatch problem under each operation scenario based on the existing network information to evaluate the transmission congestion degree of each operation scenario. Then, the scenarios with high transmission congestion degrees (i.e., major congestion scenarios) are included into the planning scenario set $\Omega_{\text {plan }}$ and feed back to the upper level. In this way, the process of feedback from the operator to the planner in the actual transmission network planning is simulated, so that the transmission network planning considering the major congestion scenario can be carried out by the upper level. The planning model takes the planning scenario set for optimization. A new generation of the target network frame is obtained for re-evaluating the transmission congestion risk in the next iteration. When no new line investment is made or there is no major congestion scenario with the congestion degree higher than the transmission congestion threshold, the planning model stops the optimization progress and 
outputs the final transmission network planning scheme. In this paper, the transmission network planning model gives priority to mitigate the operational risk of the major congestion scenario in each generation solution. The planning scenario set changes dynamically with the update of the network configuration scheme, which reflects the change of transmission congestion risk with the transmission line investment. In summary, the proposed model improves the planning efficiency and simulates the interaction between network planning and operation.

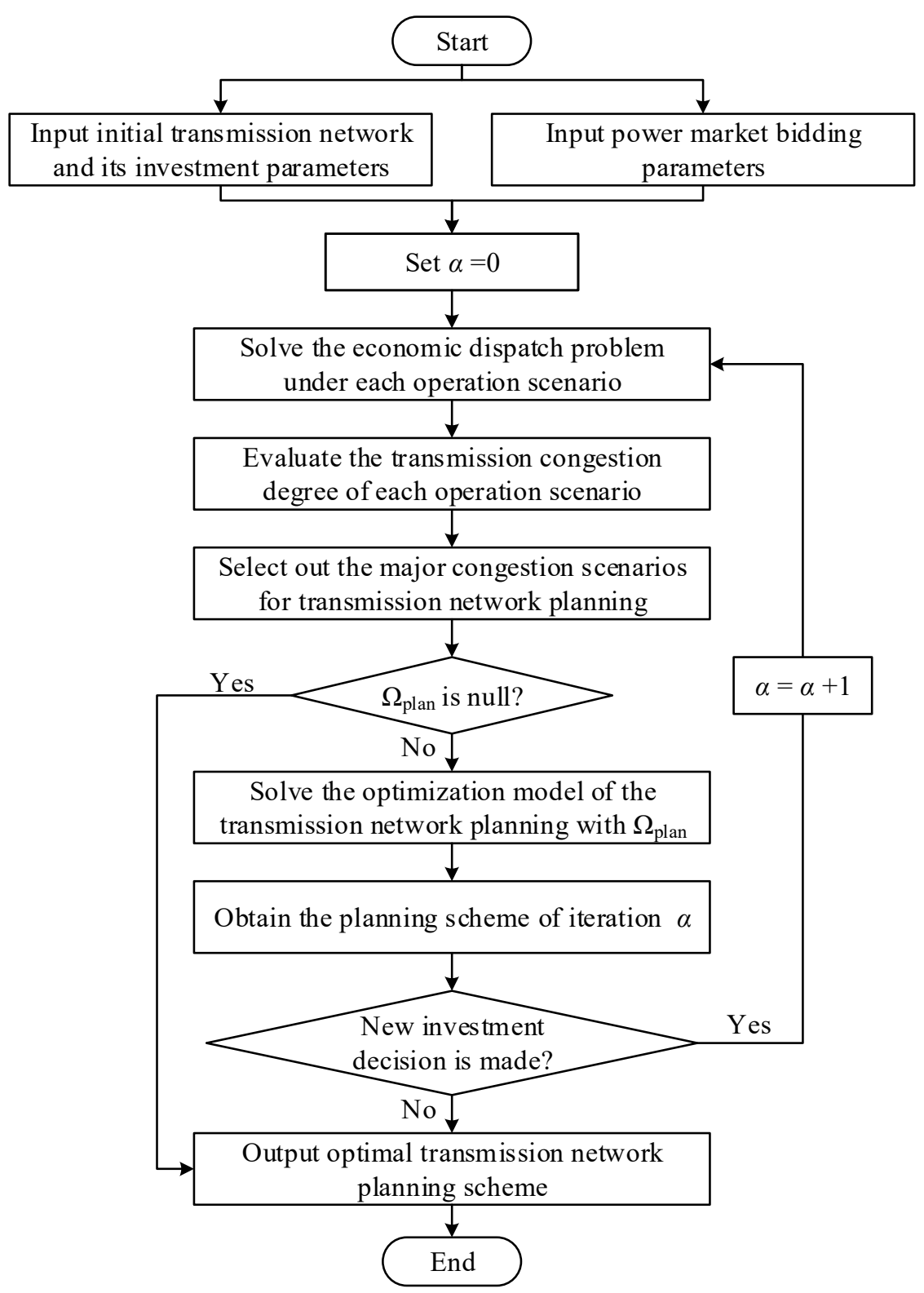

Figure 1. Bi-level collaborative planning process of transmission network.

The specific iterative solution process of the proposed bi-level collaborative planning model is as follows:

1. Input the initial transmission network and its investment parameters, and the power market bidding parameters.

2. Set the initial value of iteration time $\alpha=0$.

3. Solve the economic dispatch problem of transmission network to obtain the optimal economic dispatch scheme under each operation scenario. 
4. Evaluate the transmission congestion degree of each operation scenario.

5. Select out the major congestion scenarios for transmission network planning, which composes the planning scenario set $\Omega_{\text {plan }}$.

6. If the planning scenario set $\Omega_{\text {plan }}$ is null, return to step 9; otherwise transmit the planning scenario set $\Omega_{\text {plan }}$ to the optimization model of transmission network planning.

7. Solve the optimization model of the transmission network planning and obtain the transmission network planning scheme considering major congestion scenarios.

8. If new investment decision is made, set $\alpha=\alpha+1$ and return to step 2; Otherwise return to step 9 .

9. Output the optimal scheme and its benefit of transmission network planning.

\section{Case Studies}

The following two case studies, i.e., the improved six-node Garver power system and the simplified 25-node power system of Zhejiang Province, China, are employed for verifying the effectiveness of the proposed planning method. It is assumed that the network planning cycle is 15 years, consisting of five planning stages. The load growth rate of each stage is $5 \%$. The capital recovery cycle of the new transmission line is 25 years. The discount rate is assumed to be $8 \%$ to calculate the annual cost of transmission line investment in the planning horizon. Moreover, it is assumed that each generating unit quotes according to its marginal cost and the bid of the load demand is based on its actual benefit of electricity. The reactive power compensation equipment is configured at nodes to provide enough reactive power for balance. The proposed multi-stage transmission network planning model considering transmission congestion is a mixed integer linear programming model, which can be effectively solved through the commercial solver CPLEX [51,52] in MATLAB.

\subsection{The Improved Six-Node Garver Power System}

\subsubsection{Parameters of Case Studies}

The shown in Figure 2 contains six nodes and 15 transmission corridors. The parameters of transmission corridors are shown in Table 1. It is noted that all cost components of the improved six-node Garver power system are in US dollars. The maximum number of circuits for each transmission corridor is three. In order to simulate the characteristics of the power market, the user side loads are quoted in stages, and the loads at each node are divided into five segments. Each segment is given a different power purchase price. The output range and power supply price of different types of generating units are different. The parameters of generating units and loads are shown in Table 2 . Table 3 presents 10 types of load scenarios including ideal state, high load in developed areas, and low load in the whole network during holidays, etc. At the same time, 16 scenarios are used to simulate the changes of generator caused by equipment failures, changes of power generation prices, market policies, and other influences. The transmission congestion threshold $\eta_{0}$ is 0.3 .

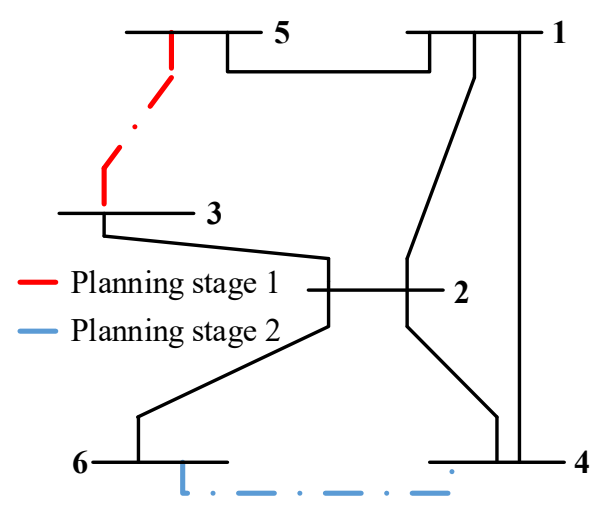

Figure 2. Topology diagram and planning scheme in the improved six-node Garver power system. 
Table 1. Parameters of transmission line in the improved six-node Garver power system.

\begin{tabular}{cccccccc}
\hline Corridor & From & To & $\begin{array}{c}\text { Reactance } \\
\text { (p.u.) }\end{array}$ & $\begin{array}{c}\text { Line Capacity } \\
\text { (MW) }\end{array}$ & $\begin{array}{c}\text { Investment } \\
\text { Cost }\left(\times \mathbf{1 0}^{\mathbf{6}} \mathbf{\$}\right)\end{array}$ & $\begin{array}{c}\text { Number of } \\
\text { Existing Lines }\end{array}$ & $\begin{array}{c}\text { Length } \\
(\mathbf{k m})\end{array}$ \\
\hline 1 & 1 & 2 & 0.40 & 80 & 40 & 1 & 20 \\
2 & 1 & 3 & 0.38 & 80 & 38 & 0 & 19 \\
3 & 1 & 4 & 0.60 & 64 & 60 & 1 & 30 \\
4 & 1 & 5 & 0.20 & 80 & 30 & 1 & 15 \\
5 & 1 & 6 & 0.68 & 56 & 68 & 0 & 34 \\
6 & 2 & 3 & 0.20 & 80 & 20 & 1 & 10 \\
7 & 2 & 4 & 0.40 & 80 & 40 & 1 & 20 \\
8 & 2 & 5 & 0.31 & 80 & 31 & 0 & 15.5 \\
9 & 2 & 6 & 0.30 & 80 & 30 & 1 & 15 \\
10 & 3 & 4 & 0.59 & 65.6 & 59 & 0 & 29.5 \\
11 & 3 & 5 & 0.20 & 80 & 20 & 1 & 10 \\
12 & 3 & 6 & 0.48 & 80 & 48 & 0 & 24 \\
13 & 4 & 5 & 0.63 & 60 & 63 & 0 & 31.5 \\
14 & 4 & 6 & 0.30 & 80 & 30 & 1 & 15 \\
15 & 5 & 6 & 0.61 & 62.4 & 61 & 0 & 30.5 \\
\hline
\end{tabular}

Table 2. Parameters of generating units in the six-node Garver power system.

\begin{tabular}{ccccc}
\hline Node & Generator No. & Capacity (MW) & $\begin{array}{c}\text { Minimum Output } \\
\text { (MW) }\end{array}$ & $\begin{array}{c}\text { Power Supply } \\
\text { Price (\$/MWh) }\end{array}$ \\
\hline 1 & G1 & 250 & 225 & 10 \\
2 & G2 & 150 & 0 & 20 \\
3 & G3 & 120 & 60 & 18 \\
4 & G4 & 80 & 0 & 22 \\
5 & - & - & - & - \\
& G5 & 120 & 60 & 17 \\
& G6 & 100 & 50 & 20 \\
6 & G7 & 100 & 0 & 15 \\
& G8 & 250 & 50 & 19 \\
& G9 & 80 & 100 & 21 \\
\hline
\end{tabular}

Table 3. Parameters of load nodes in the improved six-node Garver power system.

\begin{tabular}{cccccccccccc}
\hline & & \multicolumn{8}{c}{ Load Demand (MW) } \\
\cline { 3 - 12 } Node & $\begin{array}{c}\text { Power Purchase } \\
\text { Price (\$/MWh) }\end{array}$ & \multicolumn{10}{c}{ Scenario } \\
\cline { 3 - 12 } & & $\mathbf{1}$ & $\mathbf{2}$ & $\mathbf{3}$ & $\mathbf{4}$ & $\mathbf{5}$ & $\mathbf{6}$ & $\mathbf{7}$ & $\mathbf{8}$ & $\mathbf{9}$ & $\mathbf{1 0}$ \\
\hline 1 & $30,28,26,24,23$ & 120 & 96 & 84 & 120 & 120 & 84 & 108 & 108 & 108 & 120 \\
2 & $30,29,27,25,23$ & 120 & 96 & 84 & 120 & 120 & 84 & 108 & 108 & 108 & 120 \\
3 & $34,32,30,28,25$ & 200 & 160 & 140 & 260 & 200 & 200 & 180 & 140 & 180 & 220 \\
4 & $32,30,27,26,24$ & 150 & 120 & 105 & 150 & 150 & 150 & 135 & 105 & 135 & 150 \\
5 & $34,30,26,25,24$ & 170 & 136 & 119 & 170 & 221 & 170 & 119 & 153 & 119 & 187 \\
6 & $34,30,26,25,24$ & 130 & 104 & 91 & 130 & 130 & 130 & 91 & 117 & 91 & 130 \\
\hline
\end{tabular}

\subsubsection{Results of the Proposed Model}

The transmission planning scheme for the improved six-node Garver power system and its costs are shown in Figure 2 and Table 4, respectively. Before planning, each operation scenario of transmission network is simulated, and 23 major congestion scenarios of the transmission network are screened out. The information of major congestion scenarios is shown in Table 5. 
Table 4. Planning cost in the improved six-node Garver power system.

\begin{tabular}{cc}
\hline Type & Cost \\
\hline Line investment cost $\left(C^{\text {inv }}\right) / 10^{6} \$$ & 20.6093 \\
Line maintenance cost $\left(C^{o m}\right) / 10^{6} \$$ & 4.0995 \\
Social benefit $\left(C^{s b}\right)$ before planning $/ 10^{9} \$$ & 1.6648 \\
Social benefit $\left(C^{s b}\right)$ after planning $/ 10^{9} \$$ & 1.7026 \\
\hline
\end{tabular}

Table 5. Major congestion scenarios in improved six-node Garver power system.

\begin{tabular}{ccccc}
\hline \multirow{2}{*}{ Scenario } & Planning Stage & Probability & \multicolumn{2}{c}{ Degree of Transmission Congestion } \\
\cline { 4 - 5 } & & & Before Planning & After Planning \\
\hline 73 & 1 & $1.50 \%$ & 0.63 & 0 \\
1 & 5 & $2.40 \%$ & 0.61 & 0 \\
71 & 5 & $1.50 \%$ & 0.58 & 0.19 \\
3 & 1 & $2.40 \%$ & 0.47 & 0 \\
1 & 3 & $2.40 \%$ & 0.46 & 0 \\
1 & 4 & $2.40 \%$ & 0.46 & 0.22 \\
71 & 4 & $1.50 \%$ & 0.44 & 0 \\
2 & 4 & $2.40 \%$ & 0.44 & 0.18 \\
10 & 5 & $1.44 \%$ & 0.43 & 0.23 \\
71 & 3 & $1.20 \%$ & 0.38 & 0.26 \\
61 & 5 & $1.50 \%$ & 0.38 & 0 \\
80 & 5 & $0.90 \%$ & 0.37 & 0.15 \\
10 & $1.44 \%$ & 0.37 & 0.13 \\
81 & 4 & $1.20 \%$ & 0.35 & 0.15 \\
41 & 5 & $0.90 \%$ & 0.35 & 0.17 \\
81 & 4 & $0.45 \%$ & 0.32 & 0 \\
2 & 5 & $0.75 \%$ & 0.31 & 0 \\
2 & 5 & $2.40 \%$ & 0.31 & 0 \\
3 & $2.40 \%$ & 0.31 & 0 \\
21 & 2 & $2.40 \%$ & 0.31 & 0 \\
11 & 3 & $1.20 \%$ & 0.31 & 0.16 \\
81 & 5 & $1.20 \%$ & 0.31 & 0.30 \\
\hline
\end{tabular}

As can be seen from Table 5, the problem of transmission network congestion is not only affected by load demand growth, but also by coal control policy (scenarios 73,71 , and 80 ), gas generator price rise (scenario 81 ), large power input from upper voltage grid due to medium and long-term contracts (scenario 61), and drought or flood seasons (scenarios 21 and 11). In scenario 73, under the influence of the coal control policy, the output level of coal power of nodes 3 and 5 is reduced, the power flow of transmission corridors 11 and 14 exceed the maximum limit in the planning stage 1 , and the nuclear power with low electricity price at node 6 cannot be delivered. In order to satisfy the load demand of power users, gas generators with high electricity price are dispatched. Under scenario 1 , due to the lack of capacity to meet the demand growth in power transmission, loss of load appeared at node 4 and node 1 in planning stages 3 and 5, respectively. The loss rate of node 4 in planning stages 3 to 5 is $6.0 \%, 6.0 \%$, and $9.2 \%$, respectively, and that of node 1 in the planning stage 5 is $6.0 \%$. Scenario 1 in planning stages 3 to 5 are added to the planning scenario set. Under scenario 81 , the power supply prices of gas generators 2, 4, and 7 increase, which is higher than the quoted prices of some users at each node, resulting in loss of load. The loss of load rates of nodes 1 to 4 are $18.0 \%, 12.0 \%, 6.0 \%, 24 \%$, and $14.6 \%$, respectively. The transmission congestion fails to make full use of the low electricity price in the power system, and limits the social benefit to reach the optimal.

From Figure 2, The proposed planning model decides to build one new circuit for transmission corridor 11 and one new circuit for transmission corridor 14 in planning stage 2. The loss of load at each node in the target transmission network disappears. The degrees of transmission congestion in all 
scenarios are less than the threshold $\eta_{0}$. In Table 4 , the social benefit $\left(C^{\mathrm{sb}}\right)$ represents the sum of social benefit under all operation scenarios, which is obtained based on the simulation results considering universal scenarios. The social benefits of each planning stage increased by $0.6037 \mathrm{M} \$, 4.4072 \mathrm{M} \$$, $6.4967 \mathrm{M} \$, 9.8945 \mathrm{M}$, and $16.4156 \mathrm{M}$, respectively. After deducting the cost of transmission line planning and investment, the power network planning scheme obtained by the model can still bring the whole society with $13.1088 \mathrm{M} \$$.

To sum up, the proposed multi-stage transmission network planning model considering transmission congestion can effectively alleviate the problem of transmission congestion caused by the development of power network load and the change of power market through the optimal planning of transmission line, which improves the economic benefit of transmission network operation in the planning cycle.

\subsubsection{Influence of Different Transmission Congestion Thresholds on the Planning Scheme}

To analyze the impact of different transmission congestion threshold $\eta_{0}$ on the planning scheme, $\eta_{0}$ is set to $0.1,0.2,0.25,0.3,0.35$, and 0.4 , respectively. The planning schemes and costs are shown in Table 6 and Figure 3. As the transmission congestion threshold $\eta_{0}$ increases, the screening of major congestion scenarios tends to be loose; and the types of scenarios included in the planning scenario set increase, which changes the results of transmission network planning. When $\eta_{0}=0.4$, nine major congestion scenarios are considered in the transmission network planning. Compared with the planning scheme when $\eta_{0}=0.3$, the line expansion decision of transmission corridor 14 is delayed by one planning stage. Although the line investment cost and maintenance cost are reduced by $2.8103 \mathrm{M} \$$ and $0.0945 \mathrm{M} \$$, respectively, the social benefit is lost at the same time by $3.786 \mathrm{M} \$$, indicating the problem of insufficient transmission line investment. When $\eta_{0}=0.1$, the number of major congestion scenarios for transmission network planning is 297. Compared with the planning scheme when $\eta_{0}=0.3$, the line investment cost and maintenance cost of the resulting planning scheme are increased by $24.3564 \mathrm{M} \$$ and $0.6529 \mathrm{M} \$$, respectively. The social benefit is increased only by $1.6596 \mathrm{M}$, and the total social benefit is reduced instead. Therefore, when carrying out the transmission network planning considering the transmission congestion scenario, it is necessary to determine the reasonable transmission congestion threshold to prevent the problem of insufficient or excessive investment to realize the optimal benefit of transmission network planning.

Table 6. Comparison of transmission network planning schemes under different transmission congestion thresholds.

\begin{tabular}{cccc}
\hline$\eta_{0}$ & $\begin{array}{c}\text { Number of Severely } \\
\text { Congestion Scenarios }\end{array}$ & Planning Scheme & Solution Time/s \\
\hline 0.1 & 297 & $9(1), 11(1), 14(1), 14(2), 6(5)$ & 347.1317 \\
0.2 & 90 & $11(1), 14(1), 6(5), 14(5)$ & 42.0618 \\
0.25 & 50 & $11(1), 14(1), 6(5)$ & 35.8863 \\
0.3 & 23 & $11(1), 14(2)$ & 22.6523 \\
0.35 & 13 & $11(1), 14(2)$ & 20.5243 \\
0.4 & 9 & $11(1), 14(3)$ & 19.0354 \\
\hline
\end{tabular}

Note: In the third column, the numbers outside and inside the bracket indicate the indices of expended transmission corridors and the planning stages of the planning scheme, respectively.

The solution time of the planning model under different major congestion scenarios is shown in Figure 4. In Figure 4, as the number of severe congestion scenarios increases, so does the numbers of decision variables and constraints, which leads to the dimensionality disaster with exponential multiplication of computation. If the scale of the transmission system is further expanded, the solving difficulty will continue to increase, which makes it difficult for the model to be applied. Therefore, through the major congestion scenario screening method proposed in this paper, the optimal scheduling simulation under each operation scenario is carried out. According to the predetermined transmission 
congestion threshold, the major congestion scenario is screened in advance to obtain the planning scheme. The demand of network planning is achieved efficiently under the large scale and complex operational scenarios of the current transmission system.

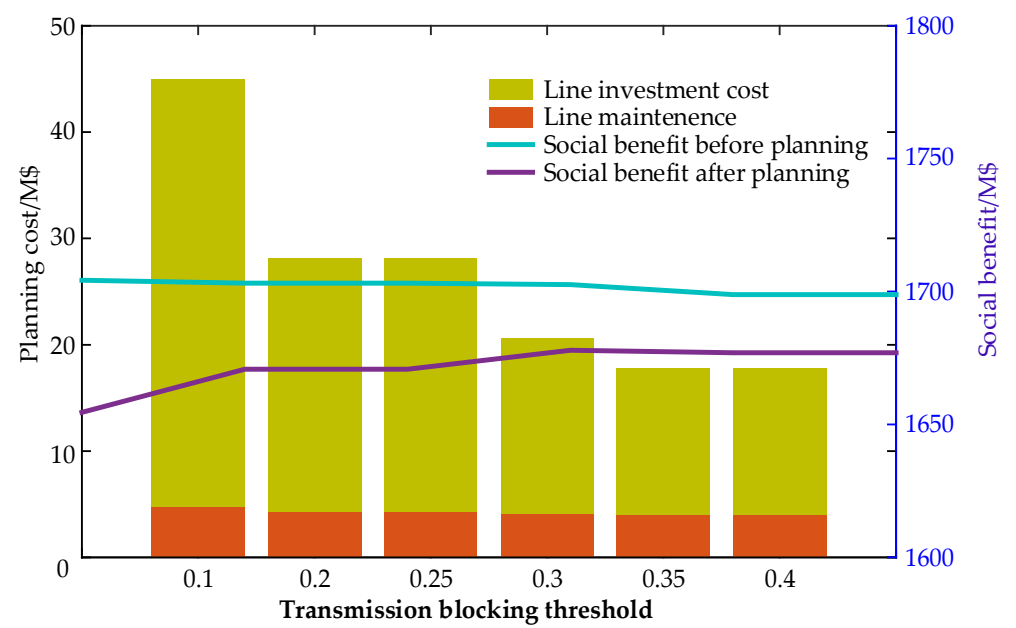

Figure 3. Planning costs under different transmission congestion thresholds.

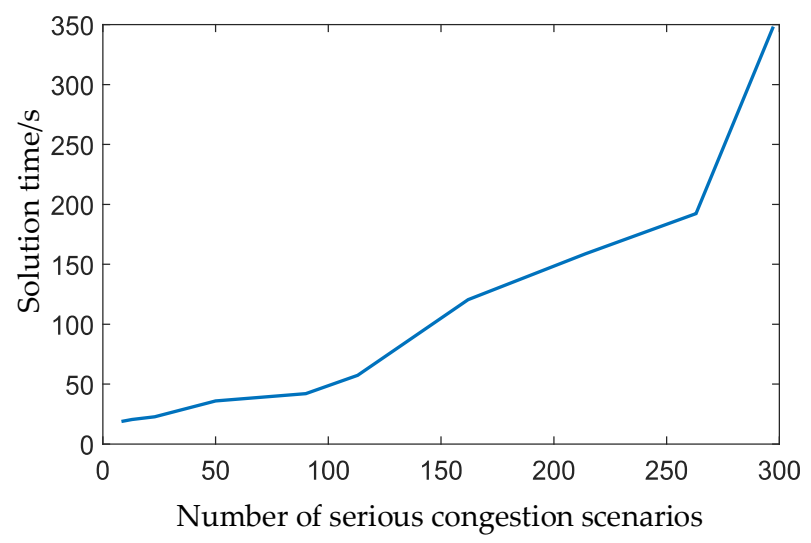

Figure 4. Solution time of the planning models with different major congestion scenarios.

\subsection{Simplified 25-Node Power System of Zhejiang Province, China}

The simplified 25-node power system of Zhejiang province, China is used for further analysis and verification. The power system consists of three $1000 \mathrm{kV}$ nodes, $22,550 \mathrm{kV}$ nodes, and 36 transmission corridors. The maximum number of lines that can be built for each transmission corridor is three. The topology of the simplified 25-node system of Zhejiang province, China is shown in Figure 5. Parameters of transmission corridors, load demands and generators in the power system are shown in Tables 7-9. It is noted that all cost components of the simplified 25-node power system of Zhejiang province, China are in Chinese Yuan (CNY). According to the actual situation of Zhejiang power market, each load node uses a unified piecewise quotation. The purchase price of each section is $316 \mathrm{CNY} / \mathrm{MWh}, 538 \mathrm{CNY} / \mathrm{MWh}, 730 \mathrm{CNY} / \mathrm{MWh}$, and $946 \mathrm{CNY} / \mathrm{MWh}$, respectively. The planning result when $\eta_{0}=7.5$ and its costs are shown in Figure 5 and Table 10. 


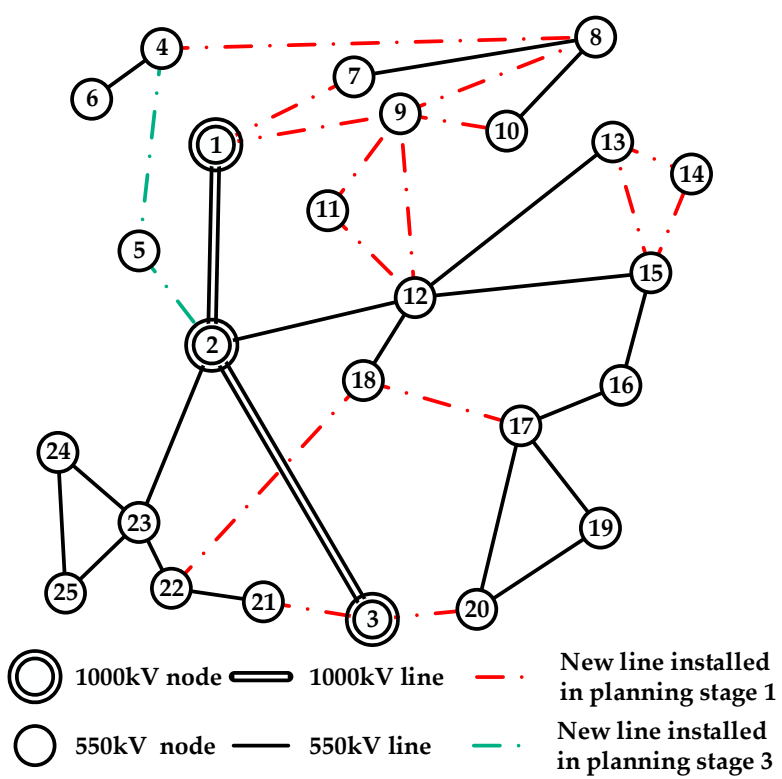

Figure 5. Topology and planning results of 25-node power system of Zhejiang province, China.

Table 7. Parameters of transmission corridors in simplified 25-node power system of Zhejiang province, China.

\begin{tabular}{|c|c|c|c|c|c|c|c|}
\hline Corridor & From & To & $\begin{array}{c}\text { Reactance } \\
\text { (p.u.) }\end{array}$ & $\begin{array}{l}\text { Capacity } \\
\text { (MW) }\end{array}$ & $\begin{array}{c}\text { Investment Cost } \\
\left(\times 10^{6} \mathrm{CNY}\right)\end{array}$ & $\begin{array}{c}\text { Number of } \\
\text { Existing Lines }\end{array}$ & $\begin{array}{c}\text { Length } \\
(\mathrm{km})\end{array}$ \\
\hline 1 & 1 & 2 & 0.00463 & 7500 & / & 2 & 100 \\
\hline 2 & 2 & 3 & 0.00281 & 7500 & / & 2 & 100 \\
\hline 3 & 2 & 5 & 0.00812 & 2200 & 348 & 2 & 87 \\
\hline 4 & 5 & 4 & 0.00145 & 2200 & 56 & 2 & 14 \\
\hline 5 & 4 & 8 & 0.00762 & 2300 & 312 & 2 & 78 \\
\hline 6 & 1 & 7 & 0.0013 & 3000 & 80 & 2 & 20 \\
\hline 7 & 7 & 8 & 0.00294 & 2200 & 120 & 2 & 30 \\
\hline 8 & 1 & 9 & 0.00425 & 4300 & 328 & 2 & 82 \\
\hline 9 & 9 & 8 & 0.00297 & 2700 & 124 & 2 & 31 \\
\hline 10 & 8 & 10 & 0.00585 & 1800 & 244 & 2 & 61 \\
\hline 11 & 9 & 10 & 0.00594 & 1800 & 240 & 2 & 60 \\
\hline 12 & 9 & 11 & 0.0034 & 3200 & 160 & 2 & 40 \\
\hline 13 & 9 & 12 & 0.00194 & 3600 & 80 & 2 & 20 \\
\hline 14 & 11 & 12 & 0.00221 & 3200 & 104 & 2 & 26 \\
\hline 15 & 2 & 12 & 0.00717 & 2700 & 294 & 2 & 73.5 \\
\hline 16 & 12 & 13 & 0.00613 & 2700 & 254.8 & 2 & 63.7 \\
\hline 17 & 13 & 14 & 0.00437 & 3700 & 180 & 2 & 45 \\
\hline 18 & 14 & 15 & 0.00276 & 2300 & 164 & 2 & 41 \\
\hline 19 & 13 & 15 & 0.00538 & 2800 & 210 & 2 & 52.5 \\
\hline 20 & 12 & 15 & 0.00608 & 3100 & 280 & 3 & 70 \\
\hline 21 & 12 & 18 & 0.00478 & 2900 & 200 & 2 & 50 \\
\hline 22 & 17 & 18 & 0.01215 & 2700 & 500 & 2 & 125 \\
\hline 23 & 16 & 17 & 0.006 & 2700 & 250 & 2 & 62.5 \\
\hline 24 & 15 & 16 & 0.00522 & 2900 & 210.8 & 2 & 52.7 \\
\hline 25 & 18 & 22 & 0.00487 & 4300 & 220 & 2 & 55.0 \\
\hline 26 & 2 & 23 & 0.01004 & 2700 & 416 & 1 & 104 \\
\hline 27 & 23 & 24 & 0.00504 & 2300 & 224 & 2 & 56 \\
\hline 28 & 24 & 24 & 0.00868 & 2700 & 368 & 2 & 92 \\
\hline 29 & 23 & 25 & 0.00658 & 2900 & 272 & 2 & 68 \\
\hline 30 & 22 & 31 & 0.00569 & 2800 & 224 & 2 & 56 \\
\hline 31 & 21 & 3 & 0.00018 & 2200 & 6.68 & 2 & 1.67 \\
\hline 32 & 3 & 20 & 0.01035 & 2200 & 400 & 2 & 100 \\
\hline 33 & 17 & 20 & 0.00487 & 2800 & 202 & 1 & 50.5 \\
\hline 34 & 17 & 19 & 0.00614 & 3700 & 255.6 & 2 & 63.9 \\
\hline 35 & 19 & 20 & 0.00269 & 2400 & 114 & 2 & 28.5 \\
\hline 36 & 4 & 6 & 0.0037 & 2200 & 149.6 & 2 & 37.4 \\
\hline 37 & 22 & 23 & 0.0019 & 2200 & 102 & 4 & 25.5 \\
\hline
\end{tabular}


Table 8. Parameters of load demand in simplified 25-node power system of Zhejiang province, China.

\begin{tabular}{|c|c|c|c|c|c|c|c|c|c|c|}
\hline \multirow{3}{*}{ Node } & \multicolumn{10}{|c|}{ Load Demand (MW) } \\
\hline & \multicolumn{10}{|c|}{ Scenario } \\
\hline & 1 & 2 & 3 & 4 & 5 & 6 & 7 & 8 & 9 & 10 \\
\hline 1 & 0 & 0 & 0 & 0 & 0 & 0 & 0 & 0 & 0 & 0 \\
\hline 2 & 0 & 0 & 0 & 0 & 0 & 0 & 0 & 0 & 0 & 0 \\
\hline 3 & 0 & 0 & 0 & 0 & 0 & 0 & 0 & 0 & 0 & 0 \\
\hline 4 & 2782 & 2504 & 2226 & 1947 & 1669 & 1391 & 2226 & 2226 & 2226 & 2782 \\
\hline 5 & 4790 & 4311 & 3832 & 3353 & 2874 & 2395 & 3832 & 3832 & 3832 & 4790 \\
\hline 6 & 90 & 81 & 72 & 63 & 54 & 45 & 72 & 72 & 72 & 72 \\
\hline 7 & 5318 & 4786 & 4254 & 3722 & 3191 & 2659 & 4254 & 4254 & 4254 & 4254 \\
\hline 8 & 9793 & 8814 & 7834 & 6855 & 5876 & 4897 & 7834 & 7834 & 7834 & 7834 \\
\hline 9 & 10,146 & 9131 & 8116 & 7102 & 6087 & 5073 & 8116 & 8116 & 8116 & 8116 \\
\hline 10 & 132 & 119 & 106 & 92 & 79 & 66 & 106 & 106 & 106 & 106 \\
\hline 11 & 0 & 0 & 0 & 0 & 0 & 0 & 0 & 0 & 0 & 0 \\
\hline 12 & 8754 & 7879 & 7003 & 6128 & 5252 & 4377 & 7003 & 7003 & 6128 & 7003 \\
\hline 13 & 2533 & 2280 & 2026 & 1773 & 1520 & 1266 & 2026 & 2026 & 1773 & 2026 \\
\hline 14 & 142 & 126 & 111 & 95 & 79 & 126 & 126 & 111 & 126 & 0 \\
\hline 15 & 13,656 & 12,290 & 10,925 & 9559 & 8194 & 6828 & 9559 & 10,925 & 9559 & 13,656 \\
\hline 16 & 1689 & 1520 & 1351 & 1182 & 1013 & 845 & 1182 & 1182 & 1182 & 1351 \\
\hline 17 & 6256 & 5630 & 5005 & 4379 & 3754 & 3128 & 4379 & 4379 & 5005 & 5005 \\
\hline 18 & 4981 & 4483 & 3985 & 3487 & 2989 & 2491 & 3487 & 3985 & 3985 & 3985 \\
\hline 19 & 857 & 771 & 686 & 600 & 514 & 429 & 600 & 514 & 686 & 686 \\
\hline 20 & 9740 & 8766 & 7792 & 6818 & 5844 & 4870 & 6818 & 5844 & 7792 & 7792 \\
\hline 21 & 2032 & 1829 & 1626 & 1422 & 1219 & 1016 & 1422 & 1626 & 1626 & 1626 \\
\hline 22 & 0 & 0 & 0 & 0 & 0 & 0 & 0 & 0 & 0 & 0 \\
\hline 23 & 1762 & 1586 & 1410 & 1233 & 1057 & 881 & 1233 & 1410 & 1410 & 1410 \\
\hline 24 & 1165 & 1049 & 932 & 816 & 699 & 583 & 816 & 932 & 932 & 932 \\
\hline 25 & 2539 & 2285 & 2031 & 1777 & 1523 & 1270 & 1777 & 2031 & 2031 & 2031 \\
\hline
\end{tabular}

The social benefit surplus is the value of the total social benefit under all scenarios deducting the transmission line investment and maintenance costs, which represents the net benefit of the transmission network planning. It can be seen from Table 10 that the social benefit surplus is $16.6 \times 10^{6} \mathrm{CNY}$, indicating that the economics of the transmission network operation is effectively improved through the proposed planning method. The information of major congestion scenarios before planning is shown in Table 11. It can be seen from Figure 5 and Table 11 that the power system is mainly faced with three types of transmission congestion scenarios, including reduction of hydraulic generator output due to drought/flood seasons, limited power generation of coal power due to coal control policy, and large power input due to medium and long-term contracts. Under scenario 71, because of the coal control policy, some coal power units at nodes 13 and 15 are shut down, and their output is halved. Due to the power flow violation of transmission corridors 12 and 14, the electricity power at node 11 cannot be sent out, resulting in loss of load at nodes 15, 16, and 17. The shadow price of scenario 71 before planning reaches 1363.6, which is higher than the shadow price of scenario $1\left(\varphi_{1}\right.$ $=1016.8$ ). However, as the probability of scenario 71 is smaller than that of scenario 1 , the degree of transmission congestion of scenario 1 is still higher than that of scenario 71 . Figure 6 shows the active power of each transmission corridor under scenario 1 before and after the planning. Under scenario 1 , the overall load level in this region is relatively high, and the transmission corridors 5, 6, 9, 11, 14, and 32 are congested, resulting in the failure of the electricity with low electricity prices being sent out from nodes $1,3,4$, and 11 . According to the planning result, new transmission lines are built in the above transmission corridors $5,6,9,11,14$, and 32 . The transmission capacity of the transmission corridor is improved, and the social benefit in this scenario is increased from $23.3 \times 10^{6} \mathrm{CNY}$ to $24.3 \times 10^{6} \mathrm{CNY}$. 
Table 9. Parameters of generators in simplified 25-node power system of Zhejiang province, China.

\begin{tabular}{|c|c|c|c|c|c|}
\hline Generator & Node & $\begin{array}{c}\text { Price } \\
\text { (CNY/MWh) }\end{array}$ & $\begin{array}{c}\text { Maximum } \\
\text { Output (MW) }\end{array}$ & $\begin{array}{c}\text { Minimum } \\
\text { Output (MW) }\end{array}$ & Type \\
\hline 1 & 6 & 367 & 1800 & 900 & Pumped storage \\
\hline 2 & 7 & 547 & 1141 & 0 & Gas generator \\
\hline 3 & 8 & 405.3 & 1320 & 528 & Coal power \\
\hline 4 & 8 & 415.3 & 2178 & 1089 & Nuclear power \\
\hline 5 & 8 & 607 & 4078 & 0 & Gas generator \\
\hline 6 & 9 & 547 & 1356 & 0 & Gas generator \\
\hline 7 & 10 & 405.6 & 4056 & 2028 & Nuclear power \\
\hline 8 & 12 & 385.3 & 2000 & 800 & Coal power \\
\hline 9 & 12 & 367 & 1200 & 600 & Pumped storage \\
\hline 10 & 12 & 607 & 904 & 0 & Gas generator \\
\hline 11 & 13 & 385.3 & 1320 & 528 & Coal power \\
\hline 12 & 13 & 547 & 680 & 0 & Gas generator \\
\hline 13 & 13 & 607 & 788 & 0 & Gas generator \\
\hline 14 & 14 & 385.3 & 2780 & 1112 & Coal power \\
\hline 15 & 15 & 385.3 & 2400 & 960 & Coal power \\
\hline 16 & 15 & 547 & 1131 & 0 & Gas generator \\
\hline 17 & 16 & 385.3 & 2400 & 960 & Coal power \\
\hline 18 & 17 & 385.3 & 2000 & 800 & Coal power \\
\hline 19 & 18 & 367 & 1500 & 750 & Pumped storage \\
\hline 20 & 18 & 607 & 186 & 0 & Gas generator \\
\hline 21 & 19 & 385.3 & 630 & 252 & Coal power \\
\hline 22 & 20 & 405.3 & 2520 & 1008 & Coal power \\
\hline 23 & 20 & 385.3 & 2000 & 800 & Coal power \\
\hline 24 & 20 & 607 & 342 & 0 & Gas generator \\
\hline 25 & 24 & 405.3 & 2520 & 1008 & Coal power \\
\hline 26 & 25 & 547 & 1323 & 0 & Gas generator \\
\hline 27 & 20 & 519.6 & 200 & 100 & Hydropower \\
\hline 28 & 20 & 656.8 & 600 & 300 & Hydropower \\
\hline 29 & 21 & 412.4 & 305 & 152.5 & Hydropower \\
\hline 30 & 25 & 386.3 & 320 & 160 & Hydropower \\
\hline 31 & 1 & 369 & 6000 & 1800 & Power from external regions \\
\hline 32 & 3 & 360 & 6000 & 1800 & Power from external regions \\
\hline 33 & 4 & 369 & 6000 & 1800 & Power from external regions \\
\hline 34 & 5 & 369 & 5000 & 1500 & Power from external regions \\
\hline 35 & 8 & 358 & 5000 & 1500 & Power from external regions \\
\hline 36 & 11 & 339 & 7500 & 2250 & Power from external regions \\
\hline 37 & 22 & 358 & 1000 & 300 & Power from external regions \\
\hline 38 & 22 & 301 & 7500 & 2250 & Power from external regions \\
\hline
\end{tabular}

Table 10. Costs of the planning scheme in 25-node power system of Zhejiang province, China.

\begin{tabular}{cc}
\hline Type & Cost \\
\hline Line investment cost $\left(C^{i n v}\right) / 10^{6} \mathrm{CNY}$ & 1826.7 \\
Line maintenance cost $\left(C^{\mathrm{om}}\right) / 10^{6} \mathrm{CNY}$ & 271.5 \\
Social benefits $\left(C^{s b}\right)$ under severe congestion scenarios $/ 10^{9} \mathrm{CNY}$ & $14,807.6$ \\
Social benefit $\left(C^{\mathrm{sb}}\right)$ surplus after planning $/ 10^{6} \mathrm{CNY}$ & 16.6 \\
\hline
\end{tabular}

Table 11. Major congestion scenarios in 25-node power system of Zhejiang province, China.

\begin{tabular}{ccccc}
\hline \multirow{2}{*}{ Scenario } & Planning Stage & Probability & \multicolumn{2}{c}{ Degree of Transmission Congestion } \\
\cline { 4 - 5 } & & & Before Planning & After Planning \\
\hline 1 & 5 & $1.6 \%$ & 16.3 & 0.5 \\
71 & 5 & $1.0 \%$ & 13.6 & 0.0 \\
2 & 5 & $2.4 \%$ & 12.5 & 1.6 \\
1 & 4 & $1.6 \%$ & 12.2 & 1.3 \\
21 & 5 & $0.8 \%$ & 10.2 & 0.0 \\
61 & 5 & $1.0 \%$ & 10.2 & 0.3 \\
1 & 3 & $1.6 \%$ & 9.1 & 0.8 \\
71 & 4 & $1.0 \%$ & 9.1 & 1.0 \\
72 & 5 & $1.5 \%$ & 9.0 & 1.0 \\
62 & 5 & $1.5 \%$ & 7.5 & 1.0 \\
\hline
\end{tabular}




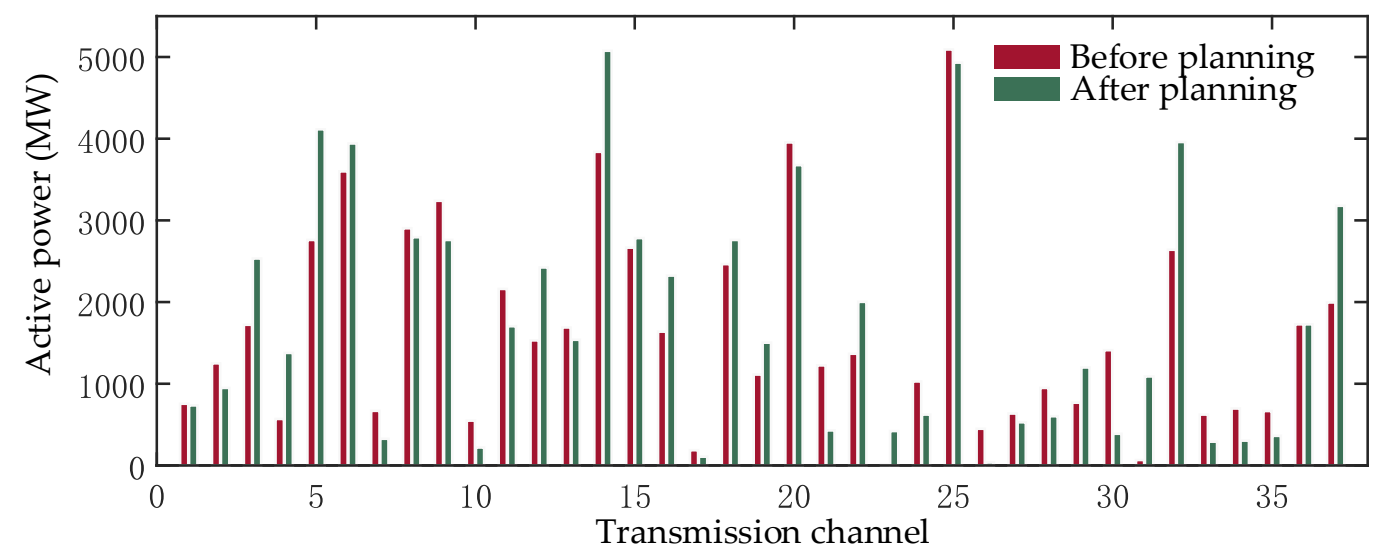

Figure 6. Active power of each transmission corridor under scenario 1.

The generating power of each generator under scenario 21 is presented in Figure 7. Under scenario 21 , nodes 20, 21, and 25 (i.e., the area with rich water resources in southwest Zhejiang) are reasonably affected by climate or generating unit scheduling. The hydropower output is less than the expected value. So, the power transmitted to node 16, 17, and 19 in southeast Zhejiang area is reduced, while the transmitted power of transmission corridor 32 reaches the upper limit. Therefore, the power from node 3 cannot be transmitted to southeast Zhejiang. Loss of load appeared at node 16, 17, and 19, with a loss rate of $12 \%, 18 \%$, and $18 \%$, respectively. At the same time, in order to meet the demand of high quoted power load, the gas generators at node 20 are called up to $342 \mathrm{MW}$. Under this circumstance, the power system is in the non-optimal operation mode. After planning, the loss of load at nodes 16, 17, and 19 disappeared; the output of node 3 increased by $1908.0 \mathrm{MW}$; and the social benefit under this scenario increased from $23.1 \times 10^{6} \mathrm{CNY}$ to $24.4 \times 10^{6} \mathrm{CNY}$.

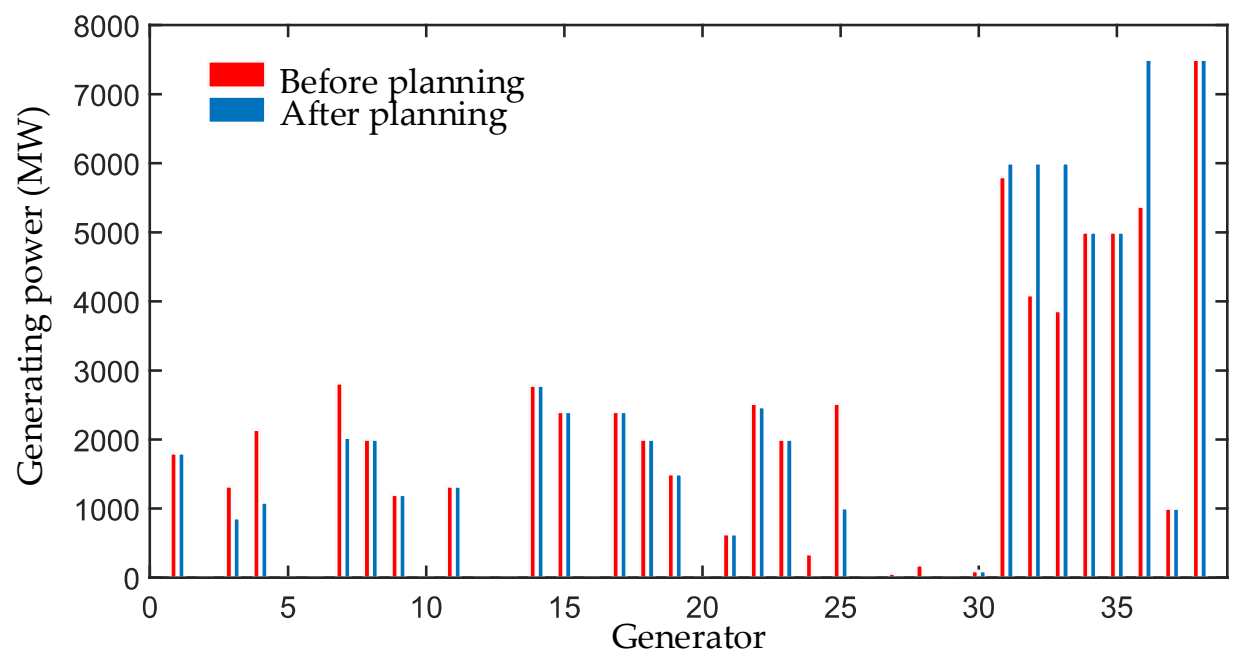

Figure 7. Generating power of each generator under scenario 21.

The proposed bi-level transmission network planning model can be used in the actual transmission network system. By analyzing the major congestion scenarios obtained in the planning, it can effectively help the power system planners to identify the power system congestion risk sources and guide the expansion construction of transmission network. 


\section{Conclusions}

The economic scheduling of transmission network is simulated to evaluate the congestion degree of each scenario and screen out the severely congested ones. A multi-stage transmission network planning model considering transmission congestion is then established. The main conclusions are as follows:

(1) Aiming at the new risks of transmission congestion in the power market, such as the fluctuation of generator quotation, the preemption of transmission medium and long-term contract, a major congestion scenario screening method based on shadow price theory is proposed, which effectively evaluates the congestion risks, screens out major congestion scenarios and provides guidance for multistage planning of transmission network.

(2) When carrying out transmission network planning with as many operating scenarios as possible, the proposed screening method of transmission network congestion scenarios effectively identifies the major congestion scenarios that need to be considered. Through the iterative optimization of transmission network planning, the optimal planning scheme is obtained to alleviate the transmission congestion risk. The proposed screening method effectively improves the efficiency of solving, prevents the dimension disaster problem, and can successfully be applied to the actual power system.

(3) Different settings of transmission congestion threshold will affect the transmission network planning results. A reasonable determination of transmission congestion threshold through sensitivity analysis can prevent the over-investment of transmission lines and reduce the difficulty and solution time.

The proposed transmission network planning model aims at maximizing the social benefit considering different scenarios, which fully describe the uncertain bidding strategies of generators and users. However, it does not take the interests of independent agents into full consideration. In fact, there is a game relationship among the independent agents in the power market, which requires multiple optimization objectives to be considered in the transmission network planning model. Future work should be concentrated on establishing the multi-objective planning model of transmission network considering multi-agent game behavior and the interests of all independent agents to improve the economy of the planning result.

Author Contributions: Conceptualization, Y.H. and L.Y.; methodology, L.Y. and Z.L. (Zhenzhi Lin); software, Y.H. and Z.Z.; validation, Y.D., K.S. and Z.L. (Zhou Lan); formal analysis, Y.H. and X.L.; investigation, Y.H.; resources, Y.D.; data curation, K.S.; writing—original draft preparation, Y.H.; writing-review and editing, X.L., Z.L. (Zhenzhi Lin) and L.Y.; visualization, K.Z.; supervision, Z.L. (Zhou Lan); project administration, Y.D., K.S., Z.L. (Zhou Lan) and K.Z.; funding acquisition, Y.D. All authors have read and agreed to the published version of the manuscript.

Funding: This research was funded by Science and Technology Program of State Grid Zhejiang Electric Power Co., Ltd. (5211JY180015), National Natural Science Foundation of China (51777185) and National Key R\&D Program of China (2016YFB0900100).

Acknowledgments: This work is supported by Science and Technology Program of State Grid Zhejiang Electric Power Co., Ltd. (5211JY180015), National Natural Science Foundation of China (51777185) and National Key R\&D Program of China (2016YFB0900100).

Conflicts of Interest: The authors declare no conflict of interest. 


\section{Nomenclature}

(1) Indices and Sets

$\begin{array}{lll}g & \text { Index for generators. } & \Omega_{\text {node }} \\ i, j & \text { Indices for nodes. } & \Omega_{i}^{\text {gen }} \\ k & \text { Index for circuits of transmission } & \Omega_{\text {plan }, t} \\ & \begin{array}{l}\text { corridor. } \\ \text { Index for scenarios. }\end{array} & \Omega_{\text {line, } i} \\ t & \text { Index for planning stages. } & \Omega_{\mathrm{dec}} \\ \alpha & \text { Index for iterations. } & L_{i j}\end{array}$

(2) Parameters

$B_{i j, k}$
$C_{s}^{\text {total }}$
$C_{s}^{s b}$
$C_{t}^{\text {inv }}$
$C_{t}^{\text {om }}$
$C_{t}^{\text {bud }}$
$c_{i j, k}^{\text {inv }}$
$c_{i j, k}^{\text {om }}$

$$
c_{i, g}^{g e n}
$$$$
c_{i}^{\text {load }}
$$$$
H_{i j}
$$$$
L M P_{i}^{\text {load }}, L M P_{i, g}^{\text {gen }}
$$$$
N_{\text {plan }}
$$$$
P_{i, g}^{g e n, \text { min }}, P_{i, g}^{g e n, \max }
$$

$$
p_{s}
$$$$
r
$$$$
S_{i j, k}^{\max }
$$

Susceptance of the $k$ th circuit of transmission corridor $i j$.

Surplus of social benefits. scenario $s$.

Investment cost of transmission line $\overline{x_{i j}}$ in planning stage $t$.

Maintenance cost of transmission line $\varepsilon_{i}^{E N S}$ in planning stage $t$.

Largest budget for the investment and $\mu_{i j}$ maintenance of transmission lines in planning stage $t$.

Unit investment cost of the $k$ th $\quad \lambda_{i}$ circuit of transmission corridor $i j$. Unit maintenance cost of the $k$ th circuit of transmission corridor $i j$.

Electricity price of generator $g$ connected with node $i$.

Power purchase price at node $i$.

$\pi$

Flow transferring relativity factor of $\overline{\omega_{i}}, \underline{\omega_{i}}$ transmission corridor $i j$.

LMPs of node $i$ and generator $g$ connected with node $i$, respectively. Number of planning stages.

$\eta_{0}$

$\eta_{s}$

Minimum and maximum power of generator $g$ connected with node $i$, respectively.

Probability of scenario $s$.

Discount rate.

Maximum transmission power of the $k$ th circuit of transmission corridor $i j$.
Social benefit under operation
Set of transmission network nodes. Set of generators connected with node $i$. Set of planning scenarios in planning stage $t$.

Set of transmission corridors starting from node $i$.

Set of decision variables.

Set of transmission circuits of transmission corridor $i j$.

$T_{h r} \quad$ Load duration of each planning stage.

$T_{\text {plan }} \quad$ Years of the planning cycle.

$T_{\text {line }} \quad$ Years of the transmission line capital recovery cycle.

Upper limit of the number of transmission line $i j$ that can be constructed.

Maximum load loss rate of node $i$.

Lagrange multiplier of the power flow constraint of power transmission corridor $i j$.

Lagrange multiplier of the power balance constraint of node $i$.

$\overline{v_{i j, k}}, v_{i j, k} \quad$ Lagrange multipliers of the upper and lower limits of capacity constraints of the $k$ th circuit of transmission corridor $i j$, respectively.

$\overline{\tau_{i, g}}, \tau_{i, g} \quad$ Lagrange multiplier of the upper and lower limits of power constraints of generator $g$ connected with node $i$, respectively. Lagrange multiplier of the phase angle constraint at equilibrium node.

Lagrange multipliers of the upper and lower limits of power losses constraint at node $i$, respectively.

Threshold of transmission congestion degree.

Transmission congestion degree of scenario $s$.

Line investment recovery coefficient.

$\varphi_{s} \quad$ Shadow price of scenario $s$.

$\zeta_{t} \quad$ Discount coefficient. 
(3) Variables

$\begin{array}{lll}P_{i}^{\text {load }} & \text { Load power of node } i . & x_{t, i j, k} \\ P_{i, g}^{\text {gen }} & \begin{array}{l}\text { Power of generator } g \text { connected with } \\ \text { node } i .\end{array} & n_{t, i j, k} \\ P_{i j}^{\text {line }} & \text { Power flow of transmission corridor } i j . & \theta_{i}, \theta_{j} \\ P_{i}^{d} & \text { Load demand at node } i . & \theta_{\text {ref }}\end{array}$

Binary investment decision variable of the $k$ th circuit of transmission corridor $i j$ in planning stage $t$.

Binary state decision variable of the $k$ th circuit of transmission corridor $i j$ in planning stage $t$.

Voltage phase angles of node $i$ and node $j$, respectively.

Voltage phase angle of the equilibrium node.

\section{References}

1. Relative Policies on Deepening the Reform of Power Industry. Available online: http://www.china-nengyuan. com/news/91900.html (accessed on 28 July 2020).

2. Zeng, M.; Yang, Y.; Wang, L.; Sun, J. The power industry reform in China 2015: Policies, evaluations and solutions. Renew. Sustain. Energy Rev. 2016, 57, 94-110. [CrossRef]

3. Sun, J.; Ruze, N.; Zhang, J.; Zhao, H.; Shen, B. Evaluating the Investment Efficiency of China's Provincial Power Grid Enterprises under New Electricity Market Reform: Empirical Evidence Based on Three-Stage DEA Model. Energies 2019, 12, 3524. [CrossRef]

4. Ni, L.; Wen, F.; Liu, W.; Meng, J.; Lin, G.; Dang, S. Congestion management with demand response considering uncertainties of distributed generation outputs and market prices. J. Mod. Power Syst. Clean Energy 2016, 5, 66-78. [CrossRef]

5. Peesapati, R.; Yadav, V.K.; Kumar, N. Transmission congestion management considering multiple and optimal capacity DGs. J. Mod. Power Syst. Clean Energy 2017, 78, 711-724. [CrossRef]

6. Zhou, L.; Zhang, D.; Wu, W.; Zhu, M.; Yang, H.; Li, C.; Li, G.; Li, F.; Cui, M. A comparative study on grid resource utilization rate between China Southern Power Grid and National Grid Plc of UK. Prot. Control. Mod. Power Syst. 2018, 3, 26. [CrossRef]

7. Huang, W.; Zhang, N.; Kang, C.; Li, M.; Huo, M. From demand response to integrated demand response: Review and prospect of research and application. Prot. Control. Mod. Power Syst. 2019, 4, 12. [CrossRef]

8. Wang, Y.; Zhang, N.; Kang, C.; Miao, M.; Shi, R.; Xia, Q. An Efficient Approach to Power System Uncertainty Analysis with High-Dimensional Dependencies. IEEE Trans. Power Syst. 2018, 33, 2984-2994. [CrossRef]

9. Freitas, P.F.S.; Macedo, L.H.; Romero, R. A strategy for transmission network expansion planning considering multiple generation scenarios. Electr. Power Syst. Res. 2019, 172, 22-31. [CrossRef]

10. Wang, Z.; Wang, W.; Liu, C.; Wang, B. Forecasted Scenarios of Regional Wind Farms Based on Regular Vine Copulas. J. Mod. Power Syst. Clean Energy 2020, 8, 77-85. [CrossRef]

11. Bompard, E.; Carpaneto, E.; Chicco, G.; Gross, G. The role of load demand elasticity in congestion management and pricing. In Proceedings of the 2000 Power Engineering Society Summer Meeting (Cat No 00CH37134) PESS-00, Seattle, WA, USA, 16-20 July 2000; Institute of Electrical and Electronics Engineers (IEEE): Piscataway, NJ, USA, 2002; pp. 2229-2234.

12. Pillay, A.; Prabhakar Karthikeyan, S.; Kothari, D.P. Congestion management in power systems-A review. Int. J. Electr. Power Energy Syst. 2015, 70, 83-90. [CrossRef]

13. Esfahani, M.M.; Yousefi, G.R. Real Time Congestion Management in Power Systems Considering Quasi-Dynamic Thermal Rating and Congestion Clearing Time. IEEE Trans. Ind. Inform. 2016, 12, 745-754. [CrossRef]

14. Khayatian, A.; Barati, M.; Lim, G.J. Integrated Microgrid Expansion Planning in Electricity Market With Uncertainty. IEEE Trans. Power Syst. 2017, 33, 3634-3643. [CrossRef]

15. Opara, R.O.; Okafor, K.C.; Dike, D.O.; Chukwudebe, G.A.; Onoshakpor, R.M. Towards Locational Marginal Pricing Model for Nigerian Electricity Tariff Structure using Optimal Power Flow Computation. In Proceedings of the 2019 IEEE PES/IAS PowerAfrica, Abuja, Nigeria, 20-23 August 2019; Institute of Electrical and Electronics Engineers (IEEE): Piscataway, NJ, USA, 2019; pp. 24-29. 
16. Shin, H.S.; Rasmusen, E. Games and Information: An Introduction to Games Theory. Econ. J. 1989, 99, 864. [CrossRef]

17. De Paola, A.; Papadaskalopoulos, D.; Angeli, D.; Strbac, G. Investigating the Social Efficiency of Merchant Transmission Planning Through a Non-cooperative Game-Theoretic Framework. IEEE Trans. Power Syst. 2018, 33, 4831-4841. [CrossRef]

18. Hesamzadeh, M.R.; Yazdani, M. Transmission Capacity Expansion in Imperfectly Competitive Power Markets. IEEE Trans. Power Syst. 2013, 29, 62-71. [CrossRef]

19. Jenabi, M.; Ghomi, S.M.T.F.; Smeers, Y. Bi-Level Game Approaches for Coordination of Generation and Transmission Expansion Planning Within a Market Environment. IEEE Trans. Power Syst. 2013, 28, 2639-2650. [CrossRef]

20. Motamedi, A.; Zareipour, H.; Buygi, M.O.; Rosehart, W.D. A Transmission Planning Framework Considering Future Generation Expansions in Electricity Markets. IEEE Trans. Power Syst. 2010, 25, 1987-1995. [CrossRef]

21. Askari, M.T.; Kadir, M.Z.A.A.; Tahmasebi, M.; Bolandifar, E. Modeling optimal long-term investment strategies of hybrid wind-thermal companies in restructured power market. J. Mod. Power Syst. Clean Energy 2019, 7, 1267-1279. [CrossRef]

22. Yang, Z.; Bose, A.; Zhong, H.; Zhang, N.; Lin, J.; Xia, Q.; Kang, C. LMP Revisited: A Linear Model for the Loss-Embedded LMP. IEEE Trans. Power Syst. 2017, 32, 4080-4090. [CrossRef]

23. Liu, M.; Quilumba, F.L.; Lee, W.-J. Dispatch Scheduling for a Wind Farm With Hybrid Energy Storage Based on Wind and LMP Forecasting. IEEE Trans. Ind. Appl. 2014, 51, 1970-1977. [CrossRef]

24. Conejo, A.J.; Castillo, E.F.; Mínguez, R.; Milano, F. Locational Marginal Price Sensitivities. IEEE Trans. Power Syst. 2005, 20, 2026-2033. [CrossRef]

25. Orfanogianni, T.; Gross, G. A General Formulation for LMP Evaluation. IEEE Trans. Power Syst. 2007, 22, 1163-1173. [CrossRef]

26. Wang, Z. A Novel Evaluation Method of Transmission Grid Performance in Power Spot Market. IEEE Access 2019, 7, 181178-181183. [CrossRef]

27. Sun, Y.; Li, Z.; Tian, W.; Shahidehpour, M. A Lagrangian Decomposition Approach to Energy Storage Transportation Scheduling in Power Systems. IEEE Trans. Power Syst. 2016, 31, 4348-4356. [CrossRef]

28. Wu, M.; Lu, Z.; Chen, Q.; Zhu, T.; Lu, E.; Lu, W.; Liu, M. A Two-Stage Algorithm of Locational Marginal Price Calculation Subject to Carbon Emission Allowance. Energies 2020, 13, 2510. [CrossRef]

29. Fang, X.; Hodge, B.-M.; Du, E.; Kang, C.; Li, F. Introducing Uncertainty Components in Locational Marginal Prices for Pricing Wind Power and Load Uncertainties. IEEE Trans. Power Syst. 2019, 34, 2013-2024. [CrossRef]

30. Mahdavi, M.; Sabillon, C.; Ajalli, M.; Romero, R. Transmission Expansion Planning: Literature Review and Classification. IEEE Syst. J. 2019, 13, 3129-3140. [CrossRef]

31. Min, C. Impact Analysis of Transmission Congestion on Power System Flexibility in Korea. Energies 2020, 13, 2191. [CrossRef]

32. Wang, J.; Zhong, H.; Tang, W.; Rajagopal, R.; Xia, Q.; Kang, C. Tri-Level Expansion Planning for Transmission Networks and Distributed Energy Resources Considering Transmission Cost Allocation. IEEE Trans. Sustain. Energy 2018, 9, 1844-1856. [CrossRef]

33. Dvorkin, Y.; Fernandez-Blanco, R.; Wang, Y.; Xu, B.; Kirschen, D.S.; Pandžić, H.; Watson, J.-P.; Silva-Monroy, C.A.; Carramolino, R.F.B. Co-Planning of Investments in Transmission and Merchant Energy Storage. IEEE Trans. Power Syst. 2018, 33, 245-256. [CrossRef]

34. Abbasi, S.; Abdi, H.; Bruno, S.; La Scala, M. Transmission network expansion planning considering load correlation using unscented transformation. Int. J. Electr. Power Energy Syst. 2018, 103, 12-20. [CrossRef]

35. Moeini-Aghtaie, M.; Abbaspour, A.; Fotuhi-Firuzabad, M. Incorporating Large-Scale Distant Wind Farms in Probabilistic Transmission Expansion Planning-Part I: Theory and Algorithm. IEEE Trans. Power Syst. 2012, 27, 1585-1593. [CrossRef]

36. Zhang, X.; Conejo, A.J. Coordinated Investment in Transmission and Storage Systems Representing Longand Short-Term Uncertainty. IEEE Trans. Power Syst. 2018, 33, 7143-7151. [CrossRef]

37. Liu, Y.; Sioshansi, R.; Conejo, A.J. Multistage Stochastic Investment Planning With Multiscale Representation of Uncertainties and Decisions. IEEE Trans. Power Syst. 2018, 33, 781-791. [CrossRef]

38. Maghouli, P.; Hosseini, S.H.; Buygi, M.O.; Shahidehpour, M. A Scenario-Based Multi-Objective Model for Multi-Stage Transmission Expansion Planning. IEEE Trans. Power Syst. 2010, 26, 470-478. [CrossRef] 
39. Li, Y.-H.; Wang, J. Flexible Transmission Network Expansion Planning Considering Uncertain Renewable Generation and Load Demand Based on Hybrid Clustering Analysis. Appl. Sci. 2015, 6, 3. [CrossRef]

40. Majidi-Qadikolai, M.; Baldick, R. Stochastic Transmission Capacity Expansion Planning With Special Scenario Selection for Integrating N-1N-1 Contingency Analysis. IEEE Trans. Power Syst. 2016, 31, 4901-4912. [CrossRef]

41. Liang, Z.; Chen, H.; Wang, X.; Ibn Idris, I.; Tan, B.; Zhang, C. An Extreme Scenario Method for Robust Transmission Expansion Planning with Wind Power Uncertainty. Energies 2018, 11, 2116. [CrossRef]

42. Zhuo, Z.; Du, E.; Zhang, N.; Kang, C.; Xia, Q.; Wang, Z. Incorporating Massive Scenarios in Transmission Expansion Planning With High Renewable Energy Penetration. IEEE Trans. Power Syst. 2020, 35, 1061-1074. [CrossRef]

43. Tor, O.B.; Guven, A.N.; Shahidehpour, M. Congestion-Driven Transmission Planning Considering the Impact of Generator Expansion. IEEE Trans. Power Syst. 2008, 23, 781-789. [CrossRef]

44. Tinney, W.F.; Bright, J.M.; Demaree, K.D.; Hughes, B.A. Some deficiencies in optimal power flow. IEEE Trans. Power Syst. 1988, 3, 676-683. [CrossRef]

45. Yan, X.; Gu, C.; Li, F.; Wang, Z. LMP-Based Pricing for Energy Storage in Local Market to Facilitate PV Penetration. IEEE Trans. Power Syst. 2018, 33, 3373-3382. [CrossRef]

46. Sadr, S.M.; Mashhadi, H.R. Evaluation of price-sensitive loads' impacts on transmission network congestion using an analytical approach. IET Gener. Transm. Distrib. 2015, 9, 523-530. [CrossRef]

47. Hajiabadi, M.E.; Samadi, M. Locational marginal price share: A new structural market power index. J. Mod. Power Syst. Clean Energy 2019, 7, 1709-1720. [CrossRef]

48. Akbari, T.; Moghaddam, S.Z. Coordinated scheme for expansion planning of distribution networks: A bilevel game approach. IET Gener. Transm. Distrib. 2020, 14, 2839-2846. [CrossRef]

49. Fang, X.; Yang, Z.; Yu, J.; Lai, X.; Xia, Q. Electricity Pricing under Constraint Violations. IEEE Trans. Power Syst. 2020, 35, 1. [CrossRef]

50. Liu, S.; Lin, Z.; Zhao, Y.; Liu, Y.; Ding, Y.; Zhang, B.; Wang, Q.; Yang, L.; White, S.E. Robust System Separation Strategy Considering Online Wide-area Coherency Identification and Uncertainties of Renewable Energy Sources. IEEE Trans. Power Syst. 2020, 1. [CrossRef]

51. Weibezahn, J.; Kendziorski, M. Illustrating the Benefits of Openness: A Large-Scale Spatial Economic Dispatch Model Using the Julia Language. Energies 2019, 12, 1153. [CrossRef]

52. Wang, G.; Tan, Z.; Lin, H.; Tan, Q.; Yang, S.; Ju, L.; Ren, Z. Multi-Level Market Transaction Optimization Model for Electricity Sales Companies with Energy Storage Plant. Energies 2019, 12, 145. [CrossRef] 